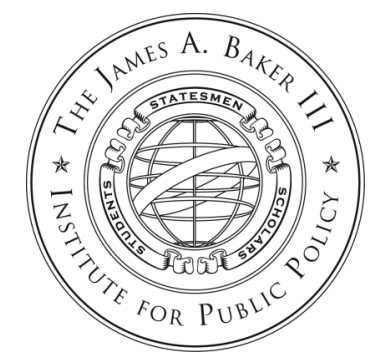

James A. Baker III Institute for Public Policy

RICE UNIVERSITY

\title{
ECONOMICS OF PRICING THE COST OF CARBON DiOXIDE RESTRICTIONS IN THE PRODUCTION OF ELECTRICITY
}

\author{
BY \\ DAGOBERT L. BRITO \\ Rice Scholar, James A. Baker III Institute for Public Policy \\ PETERKIN PROFESSOR OF POLITICAL ECONOMY, Rice UNIVERSITY \\ AND \\ Robert F. CURL \\ Rice Scholar, James A. Baker III Institute for Public Policy \\ Pitzer-Schlumberger Professor of Natural SCiences Emeritus and \\ Professor of Chemistry EMERITUS, Rice University
}

JULY 1, 2010 


\section{Economics of Pricing the Cost of $\mathrm{CO}_{2}$}

THESE PAPERS WERE WRITTEN BY A RESEARCHER (OR RESEARCHERS) WHO PARTICIPATED IN A BAKER INSTITUTE RESEARCH PROJECT. WhEREVER FEASIBLE, THESE PAPERS ARE REVIEWED by OUTSIDE EXPERTS BEFORE THEY ARE RELEASED. HOWEVER, THE RESEARCH AND VIEWS EXPRESSED IN THESE PAPERS ARE THOSE OF THE INDIVIDUAL RESEARCHER(S), AND DO NOT NECESSARILY REPRESENT THE VIEWS OF THE JAMES A. BAKER III INSTITUTE FOR P UbLiC POLICY.

(C) 2010 by the james A. Baker III Institute for Public Policy of Rice University

THIS MATERIAL MAY BE QUOTED OR REPRODUCED WITHOUT PRIOR PERMISSION, PROVIDED APPROPRIATE CREDIT IS GIVEN TO THE AUTHOR AND THE JAMES A. BAKER III INSTITUTE For PUBLIC POliCy. 


\begin{abstract}
One of the more difficult issues in the debate over policy to reduce carbon dioxide emissions is calculating the cost of a carbon dioxide constraint. In this paper, we calculate the cost of a carbon dioxide constraint in the production of electricity by modeling the replacement of coal generators with natural gas generators. We find:

1. Replacing coal generators with natural gas generators is the most economical way to achieve a target of reducing carbon dioxide emissions by 20 percent.

2. Unless there is a technological breakthrough in carbon sequestration, the carbon intensity of coal means that "clean coal" cannot be a significant factor in reducing carbon dioxide. Replacing existing coal generation capacity with modern coal generation plants can only reduce total carbon dioxide by 5 percent.

3. The distribution of the efficiency of coal generators in the United States is very concentrated. This concentration restricts the range over which carbon dioxide prices effectively manage the displacement of coal by gas. At current prices for fuels, a carbon price of approximately $\$ 30 /$ metric ton (MT) will shut down 10 percent of coal generator capacity, and a price of $\$ 45 / \mathrm{MT}$ will shut down 90 percent of coal generator capacity.

4. The narrow range for the price of carbon dioxide means that coal generator capacity is very sensitive to the price of carbon dioxide emissions. This creates the possibility that a market in carbon dioxide permits will result in high volatility in the market for electricity.

5. The carbon prices implied by the transition from coal to gas will have very little impact on transportation fuels. Consumption of transportation fuels would only be reduced by about 5 percent or less by carbon dioxide prices that are compatible with the transition from coal to gas.
\end{abstract}




\section{Introduction*}

One of the more difficult issues in the debate over policy to reduce carbon dioxide emissions is calculating the cost. The only way to do so directly is to use a dynamic general equilibrium model. A dynamic general equilibrium model could be used to calculate the growth path of the economy and the impact that a constraint on the consumption of carbon dioxide would have on growth and welfare. However, dynamic general equilibrium models are very complicated. They can only be solved on a computer, and it is necessary to make many implicit assumptions about structure and explicit assumptions about parameter values. This complexity limits the value of the models in the political discourse. A biased party can achieve a desired result with less-thantransparent assumptions or pick the model that supports their political agenda. At the present time, there are many models that predict the cost of carbon dioxide, with a range in results that vary by at least a factor of five. ${ }^{1}$

Our goal in this paper is more limited. We propose to calculate the cost of a carbon dioxide constraint in the production of electricity as a function of the price of fuels. We calculate the cost of a carbon dioxide constraint in a model where the assumptions are transparent and the model is relatively simple. The mathematics used to derive the model is common in many technical fields. The derivation of the model can be checked with a few hours of work. The resulting equations are simple and can be solved with a spreadsheet.

This simplicity comes at a cost. This paper models the displacement of coal generation by gas, so the forecast period is probably on the order of 20 years. ${ }^{2}$ Beyond that period, reductions in carbon dioxide must come from reductions in transport fuels or the replacement of gas electricity generation by nuclear power or renewables, etc. This transition may be very costly or not, depending on technical advances. Prediction of technical change is very difficult, and the technologies available 20 years in the future are probably not the main element driving the current debate.

\footnotetext{
${ }^{*}$ We would like to thank Jonathan Hamilton, Peter Hartley, and Kenneth Medlock for their help and comments. All errors are the responsibility of the authors.

${ }^{1}$ See Stern, N. The Stern Review, pp. 318-348.

${ }^{2}$ For a discussion of the displacement of coal by gas, see Kaplan, Displacing Coal with Generation from Existing Natural Gas-Fired Power Plants, 2010.
} 
The parameters used in our calculations are readily available in the public domain. Most of the parameters are reported in the 2009 Update of the 2003 MIT Report: The Future of Nuclear Power, and the supporting literature. The other important data we use is the distribution heat rates for coal generators in the United States. This data is available from the Energy Information Agency. ${ }^{3}$

We assume that at present, and for at least the next decade, base load electrical generation capacity will come from coal and natural gas, and the process of reducing carbon dioxide emissions in the United States will be substantially through the displacement of coal-fired generation by natural gas. These two fuels have different carbon intensities, with the amount of carbon dioxide per kilowatt-hour $(\mathrm{kWh})$ produced by natural gas being less than the amount produced by coal. The difference in carbon intensity between marginal coal generators and natural gas generators allows us to calculate the cost of a carbon dioxide constraint. The technologies involved are linear. If at any point in time the price of electricity is greater than the cost of producing electricity using base load capacity, then that base load capacity will operate at full output.

Electrical production accounts for approximately 40 percent of the carbon dioxide produced in the United States. Coal produces about 33 percent of U.S. carbon dioxide emissions, which translates into about 81 percent of carbon dioxide emissions in the production of electricity. Replacing existing coal generation capacity with modern coal generation plants can only reduce total carbon dioxide by 5 percent. ${ }^{4}$ Unless there is a technological breakthrough in carbon sequestration, the carbon intensity of coal means that "clean coal" cannot be an important factor in reducing carbon dioxide. However, through the development of nontraditional sources of

\footnotetext{
${ }^{3}$ Energy Information Agency, EIA 923.

${ }^{4}$ In 2008 , total U.S. $\mathrm{CO}_{2}$ emissions were $5.92 \times 10^{9}$ metric tons $; 1.95 \times 10^{9}$ metric tons were produced by coal generating electricity. $1.99 \times 10^{9} \mathrm{Mwh}$ were produced by coal generators. The $\mathrm{CO}_{2}$ that would be produced if the existing stock of coal generators were replaced by modern generators (using MIT numbers for modern coal generators) is:

$1.99 \times 10^{9} \mathrm{Mwh} \times .839 \frac{\text { tons }}{\mathrm{Mwh}}=1.67 \times 10^{9}$ tons or $\frac{(1.95-1.67) \times 10^{9} \text { tons }}{5.92 \times 10^{9} \text { tons }} \times 100=4.98$ percent. See http://www.eia.doe.gov/cneaf/electricity/epa/epa sum.html, Table 2.1, and http://www.eia.doe.gov/oiaf/1605/ggrpt/flowchart.html.
} 
natural gas, the United States is in the fortunate position of having enough new natural gas production coming online to make it possible to shift electricity generation from coal to natural gas, with a concomitant reduction in carbon dioxide emissions. ${ }^{5}$ It is still doubtful whether natural gas supplies will be adequate to maintain this shift; therefore, development of nuclear and renewable electricity generation will need to continue at a rapid pace.

While electricity production amounts to less than half of the energy used in the United States, its central role in the reduction of carbon dioxide emissions is guaranteed by the fact that there is a transition technology to sources that emit less and, eventually, to sources that are carbon-neutral. Consumption of transportation fuels that produce two billion metric tons (MT) of carbon dioxide would only be reduced by about 5 percent or less by carbon dioxide prices that are compatible with the elimination of coal generators ${ }^{6}$ (see Table 1 , page 20 ). Thus, it might be necessary to decouple the pricing of allocations for transportation fuel from the allocations for the production of electricity.

\section{The Model}

The equations that we use to calculate the cost of carbon dioxide can be derived intuitively and without much mathematical complexity if we make some very strong simplifying assumptions. First, assume that gas generators are competing with coal generators to provide base load power, where by base load power we mean electricity when demand is lowest. Second, assume that all coal generators are identical (this assumption will be dropped) and that all gas generators are identical. Third, assume that the price of electricity is constant. Fourth, assume that the market for electricity is in equilibrium. Given these assumptions, the equations that can be used to

calculate the marginal cost of a carbon dioxide constraint in the production of electricity from coal and gas are

$$
\begin{aligned}
& \bar{p}=\pi a_{1}+b_{1}+c_{1}+d_{1} \\
& \bar{p}=\pi a_{2}+b_{2}+c_{2}+d_{2}
\end{aligned}
$$

\footnotetext{
${ }^{5}$ For a discussion of some of the institutional problems in a transition from coal to gas see Wolak, F., "Regulatory Barriers to Lowering the Carbon Content of Energy Services.

${ }^{6}$ EIA, Emissions of Greenhouse Gases in the United States 2007, p. 14, Table 6.
} 
where the price of electricity is $\bar{p}$, the amount of carbon dioxide produced (MT per megawatthours, or MWh) is $a_{1}$ for coal and $a_{2}$ for gas. The allocated fixed-cost per MWh is $b_{1}$ for coal and $b_{2}$ for gas. The cost of fuel is $c_{1}$ for coal and $c_{2}$ for gas. Nonfuel variable costs (overhead and maintenance) are $d_{1}$ for coal and $d_{2}$ for gas. The units of cost are dollars per megawatt-hour. These costs and parameters are available in the literature. ${ }^{7}$ The cost of carbon dioxide per metric ton is $\pi^{8}$

The right-hand sides of equations (1) and (2) are the costs of producing electricity by coal and gas, respectively. If the market is in equilibrium, then the cost of electricity should be the same under conditions where the carbon dioxide cost is binding for both sources, so:

$$
\pi a_{1}+b_{1}+c_{1}+d_{1}=\pi a_{2}+b_{2}+c_{2}+d_{2}
$$

If we solve for the cost of carbon dioxide that would satisfy this relationship, $\pi$, we get

$$
\pi=\frac{\left(b_{2}-b_{1}\right)+\left(c_{2}-c_{1}\right)+\left(d_{2}-d_{1}\right)}{a_{1}-a_{2}}
$$

for the case where coal and gas are sufficient to meet the needs. The mathematical complexity introduced in the appendix is needed to derive this equation without making these strong simplifying assumptions.

There are three complications. First, the demand for electricity is not constant, but varies over time both daily and seasonally. The output of gas turbine generators can be varied rapidly, and the primary cost in gas generation is the cost of fuel. On the other hand, coal and nuclear output cannot be changed rapidly, making it virtually impossible to take advantage of hourly, or even daily, fluctuations in electricity prices caused by changes in demand.

The second complication is that, at the present time, there exists a large stock of coal generation capacity that ranges widely in efficiency and age. Thus, the assumption that all coal generators

\footnotetext{
${ }^{7}$ We use Du and Parsons, Update of Cost of Nuclear Power, May 2009. This is the support paper for 2009 Update of the 2003 MIT Report: The Future of Nuclear Power.

${ }^{8}$ Carbon dioxide is a stock externality. For a discussion of stock externalities see Kolstad C., "Fundamental irreversibilities in stock externalities," and Laffont, J.J. and J. Tirole, "Pollution permits and compliance strategies."
} 
are identical cannot be correct. The assumption that gas generators are identical does not cause problems because we are assuming that existing coal generation capacity is being displaced by new gas generators.

The third complication is the assumption that the markets are in equilibrium. If the markets are in equilibrium, the cost of a capital investment should equal the present value of the income stream it generates. If gas and coal were competing at the margin, then a tax on carbon dioxide would reduce the income stream of a coal generator more than it would reduce the income stream of a gas generator. If the gas plant is not earning quasi-rents, then the present value of the income stream of the coal plant is less than the capital cost. However, coal plants have a life of 30 years or longer, and the investment is a sunk cost. Existing coal plants will not shut down as long as the average price of electricity over the price cycle is greater than or equal to the average variable cost, which depends on the cost of fuel, the cost of carbon dioxide, and the efficiency of the generator. We calculate the cost of carbon dioxide emissions at which a coal plant of a given heat rate will shut down.

In the appendix, we drop the simplifying assumptions and derive a slightly more complicated form of equations (1) and (2). The equations, which are derived in the appendix, are

$$
\begin{gathered}
\frac{\int_{0}^{T} p(t) d t}{T}=\pi a_{1 j}+b_{1 j}+c_{1 j}+d_{1 j}, j=1, N \\
\frac{\int_{0}^{T} p(t) d t}{T}=\pi a_{2}+b_{2}+c_{2}+d_{2}
\end{gathered}
$$

where $p(t)$ is the price of electricity revenue $(\$ / \mathrm{MWh})$ over the period $[0, T]$, and $\frac{\int_{0}^{T} p(t) d t}{T}$ is the average price. Note that equation (5) is now indexed by the subscript $j$ to reflect that the stock of coal generators differs in efficiency. 


\section{The Cost of a Carbon Dioxide Constraint}

We are going to calculate the relationship between the cost of a carbon dioxide constraint and the reduction in carbon dioxide emissions that results from replacing coal generators with gas generators. We will use equations (5) and (6) to calculate the cost of carbon dioxide emissions that will make a coal generator of a given heat rate marginal. We will then use the distribution of heat rates of coal generators in the United States to calculate the cost of carbon dioxide per metric ton that will result in a given reduction in carbon dioxide emission in the generation of electricity.

We used the 2009 MIT study as the base case to define the parameter values. The MIT study assumes that a modern coal generator has a heat rate of 8,870 British thermal units (BTU) per kWh and produces .839 MT of carbon dioxide per MWh. ${ }^{9}$ The capital cost, $b_{1}$, is $\$ 28$ per MWh and overhead and maintenance costs, $d_{1}$, are $\$ 8$ per MWh. A modern gas generator has a heat rate of 6,800 BTU per kWh and produces .361 MT of carbon dioxide per MWh. The capital cost, $b_{2}$, is $\$ 10$ per MWh and overhead and maintenance costs, $d_{2}$, are $\$ 2$ per MWh. [Note: In order to convert the fixed cost of capital (\$/MW) into a cost that depends upon output (\$/MWh), assumptions have been made about the total number of hours of operation.]

Since the emission of carbon dioxide is proportional to fuel consumption, we explicitly recognize that the carbon dioxide output of a coal generator is a function of its heat rate $R_{j}$ (BTU per $\mathrm{kWh}$ ), using the MIT data as a base. It is convenient to define

$$
a_{1}\left(R_{j}\right) \equiv a_{1 j}=\left(\frac{.839}{8,870}\right) R_{j} \equiv a_{10} R_{j}
$$

\footnotetext{
${ }^{9}$ The MIT study uses kilowatts and kilograms. Since our interest in the cost of carbon dioxide emissions and the units used are dollars per metric ton, it is more convenient to use megawatts and metric tons in the paper. The only exception will be heat rates, as the standard usage is BTU/kWh. The cost data for the calculations is the support paper for the MIT update, Du and Parsons (2009), pp. 20-32.
} 
where we define $a_{10}=\left(\frac{.839}{8,870}\right)$. The other important variable that varies with heat rate is fuel cost. We recognize that the variable fuel cost for coal per MWh is a function of the heat rate of the generator

$$
c_{1 j}=\left(R_{j} \times 10^{-3}\right) q_{1}
$$

where $q_{1}$ is the cost of coal in $\$ / \mathrm{MMBTU}$ (million BTU) and $R_{i}$ is the heat rate in $\mathrm{kWh} / \mathrm{BTU}$. We assume, as mentioned above, that $c_{2}$ is the same for all gas generators and $q_{2}$ is the cost of gas in $\$ / M M B T U$, so $c_{2}=6.8 q_{2}$. Note that at the point where a coal plant is marginal, the present value of the income stream associated with that capital is zero, so the economic value of that plant is zero. Technically, the Lagrange multiplier associated with a nonbinding constraint is zero. This means that the term $b_{1 j}=0$, if a generator with the heat rate $R_{j}$ is marginal.

Solving equations (5) and (6) for $\pi$ and defining $R_{k}$ as the heat rate of the marginal generator, the solution can be written as

$$
\pi_{k}=\frac{b_{2}+\left(c_{2}-c_{1 k}\right)+\left(d_{2}-d_{1 k}\right)}{a_{1 k}-a_{2}}=\frac{b_{2}+\left[6.8 q_{2}-\left(R_{k} \times 10^{-3}\right) q_{1}\right]+\left(d_{2}-d_{1 j}\right)}{a_{10} R_{k}-a_{2}}
$$

where $\pi_{k}$ is the cost per metric ton of carbon dioxide emissions that would make a gas generator with a heat rate $R_{k}$ marginal. This value depends on the cost of coal and gas as fuels and the capital cost of gas generators. Let equation (9) define the function $\pi=f(R)$. This notation will be useful later in the paper.

These values of $\pi_{k}$ as a function of $R_{k}$ are plotted in Figure 1 for coal at $\$ 1.50$ per MMBTU and for gas at \$5 per MMBTU. These figures reflect March 2010 prices. ${ }^{10}$ We recognize that our

\footnotetext{
${ }^{10} \mathrm{http}: / /$ www.eia.doe.gov/dnav/ng/hist/n3045us3m.htm. Note that in March 2010, the last price available was for November 2009.
} 
model is sensitive to the relative prices of heat from the two sources. We use these prices as an example and will consider later the possible range of fuel costs.

\section{Figure 1}

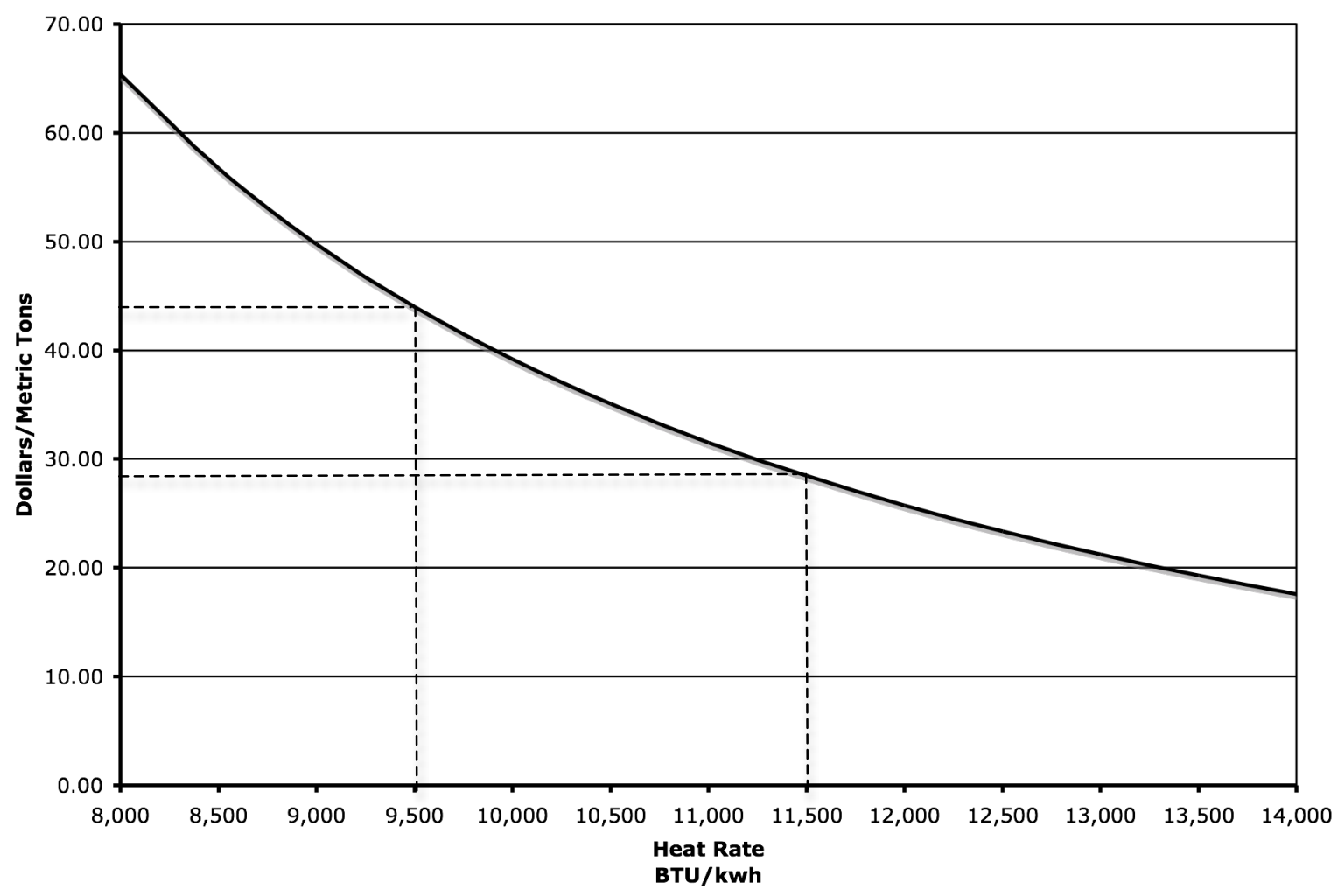

Price of carbon dioxide as a function heat rate for coal at $\$ 1.50$ per MMBTU and for gas at $\$ 5$ per MMBTU. The vertical dashed lines encompass 90 percent of the coal electrical generation capacity. The horizontal dashed lines are the carbon dioxide prices that would make the plants to the right of the vertical dashed lines uneconomical for the assumed fuel prices. 
Figure 2, below, gives the distribution of the heat rates for coal generators in the United States by capacity.

Figure 2

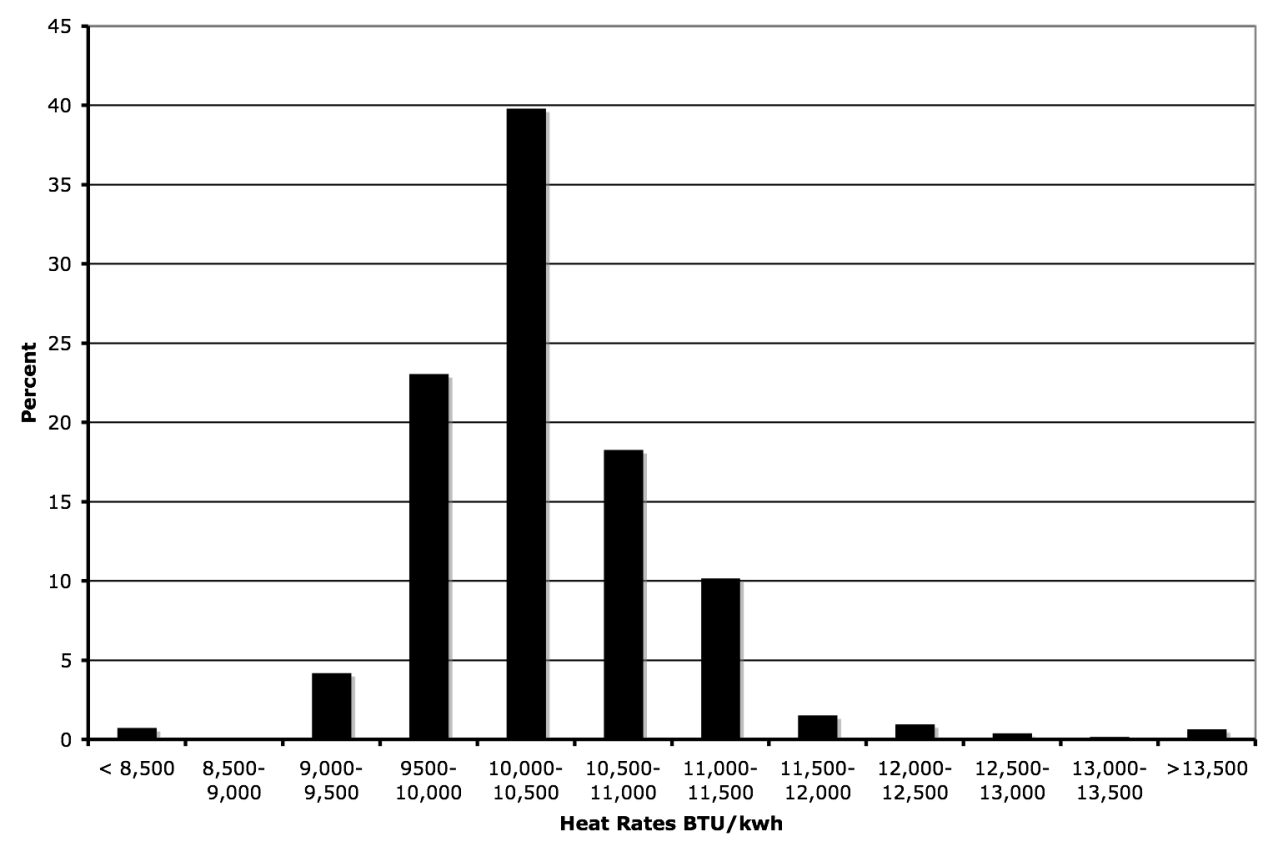

Distribution of heat rates for U.S. coal plants. ${ }^{11}$

Approximately 4 percent of coal generators have a heat rate greater than 11,500 BTU/kWh; 90 percent of coal generators have a heat rate between 9,500 BTU/kWh and 11,500 BTU/kWh; and 6 percent of coal generators have heat rates less than 9,500 BTU/kWh. Thus, a carbon dioxide price of $\$ 28.50 / \mathrm{MT}$ would cause 10 percent of coal generation capacity to shut down. A carbon dioxide price of $\$ 45 / \mathrm{MT}$ would cause 95 percent of coal generation capacity to shut down. (See Table 2, below, for a distribution of coal generation capacity by 100 BTU bins.) These numbers may seem high, but they represent the shutdown point of existing coal generators. The shutdown point is when average variable cost is greater than price. Equation (9) and the distribution of coal generator capacity can be used to calculate the price of carbon dioxide emissions as a function of the amount of coal generator capacity shut down.

\footnotetext{
${ }^{11}$ EIA 923 database.
} 
Define $\gamma(R)$ as the density function for the distribution of coal generators. Since coal generators with the highest heat rates are the first to be shut down, it is useful to define the cumulative distribution function as

$$
S(R)=\int_{R}^{\bar{R}} \gamma(s) d s
$$

where $S(R)$ is the fraction of coal generators that have a heat rate greater than or equal to $R$, and $\bar{R}$ is the highest heat rate of the coal generator stock. Let $R=g(S)$ be the inverse of equation (10). Recall that equation (9) defines the function $\pi=f(R)$, so

$$
\pi=f[g(S)]
$$

defines the relationship between the price of carbon dioxide emissions and the amount of generator capacity that has shut down. This relationship is plotted in Figure 3, below.

\section{Figure 3}

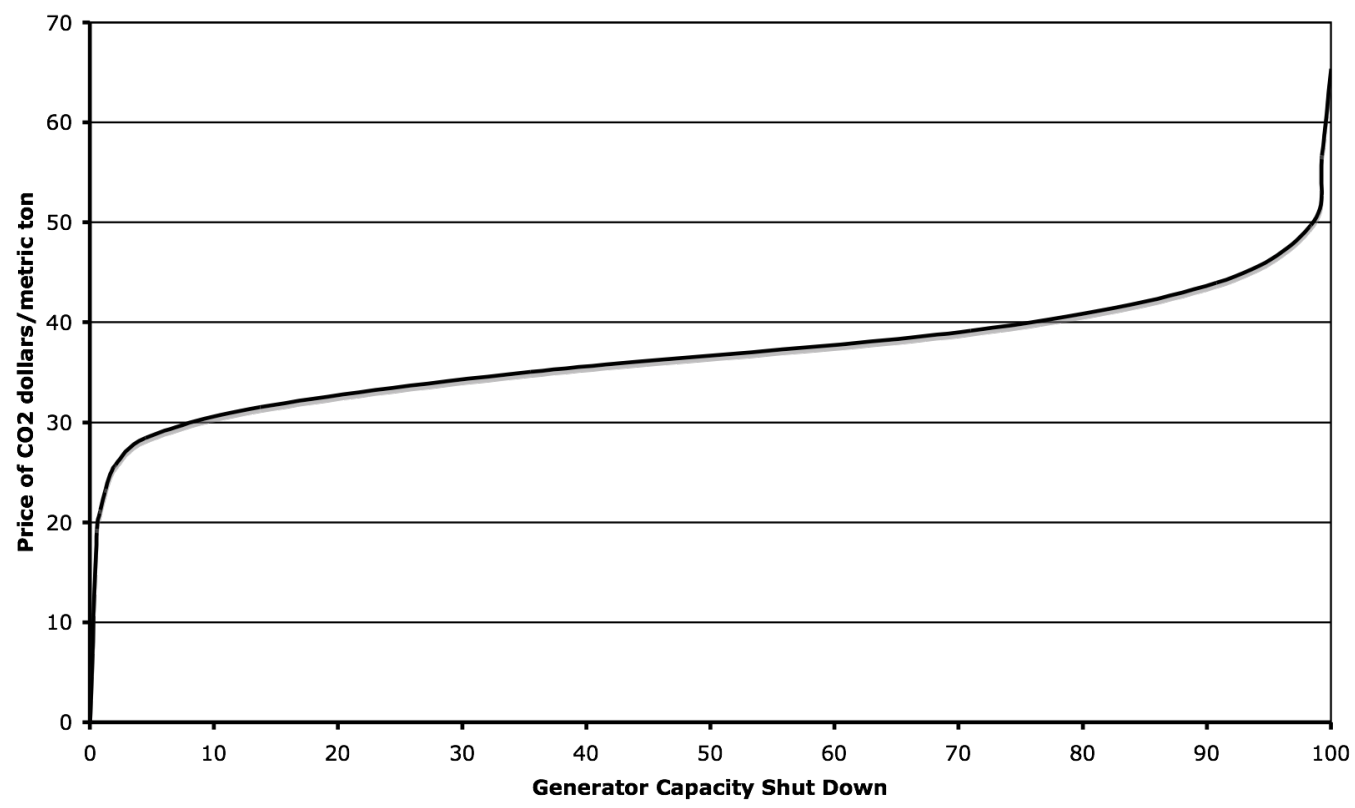

Price of carbon dioxide as a function of coal generator capacity shut down. Assumed price of coal is $\$ 1.50 \mathrm{MMBTU}$ and price of gas is $\$ 5 \mathrm{MMBTU}$. 
The heat rates of coal generators are concentrated in a relatively narrow range with approximately 80 percent of coal generator capacity having a heat rate between 9,500 BTU/kWh and 11,000 BTU/kWh (see Table 2, below). This is illustrated in detail in Figure 3. At current fuel prices, a price for carbon dioxide emissions of \$30/MT will shut down less than 10 percent of coal generating capacity, and a price for carbon dioxide emissions of \$45/MT will shut down over 90 percent.

This suggests the possibility of instabilities in the electricity supply system in a cap-and-trade environment. The slope of the carbon dioxide price, $\frac{d \pi}{d S}$, where $\mathrm{S}$ is percent of generator shut down, is illustrated in Figure 4, below. If we examine Figure 4, we see that $\frac{d \pi}{d S}<.5$ for $10<S<90$ and $\frac{d \pi}{d S}<.25$ for $20<S \leq 90$. The average over this interval is approximately 0.17 .

Figure 4

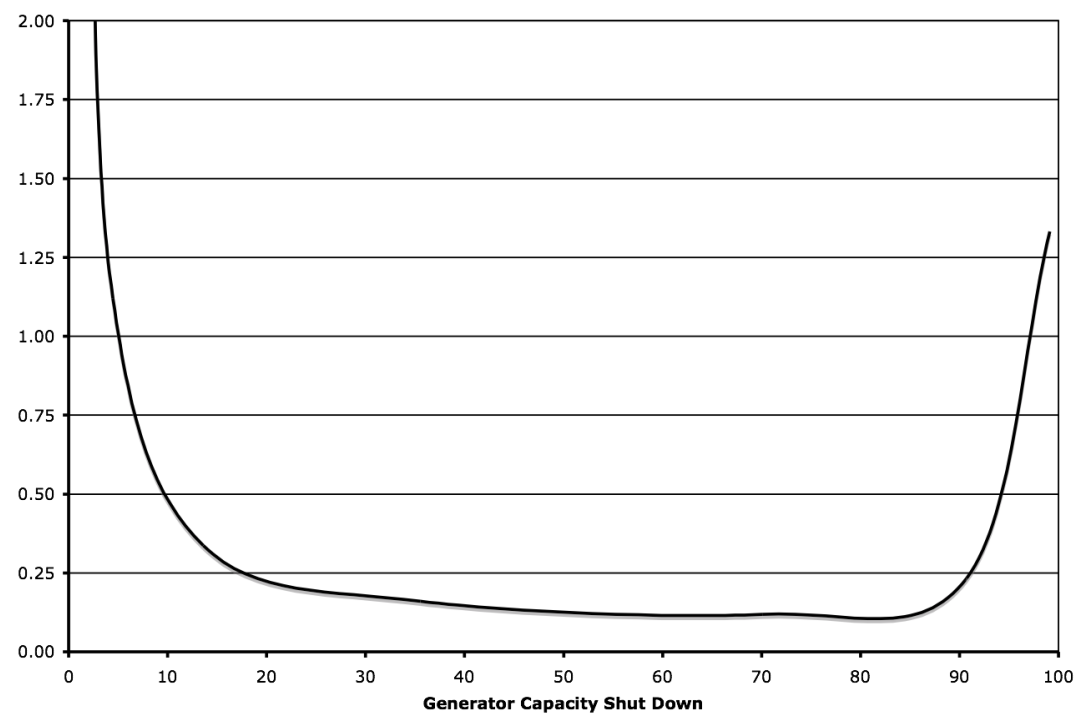

Slope of the price of carbon dioxide curve of Fig. 3 vs. coal generator capacity shut down

An implication of the concentration of the distribution of coal generator capacity is that as coal generation capacity responds to the price of carbon dioxide emissions, there may be volatility in 
the supply of electricity. Economists define the price elasticity of a quantity with respect to a price as

$$
\text { Elasticity }=\frac{\text { Percentage change in Quantity }}{\text { Percentage Change in Price }}
$$

The elasticity of coal generator capacity, $\eta_{\pi}$ is

$$
\eta_{\pi}=\frac{\pi}{S} \frac{d S}{d \pi}
$$

\section{Figure 5}

Elasticity of Coal Generators

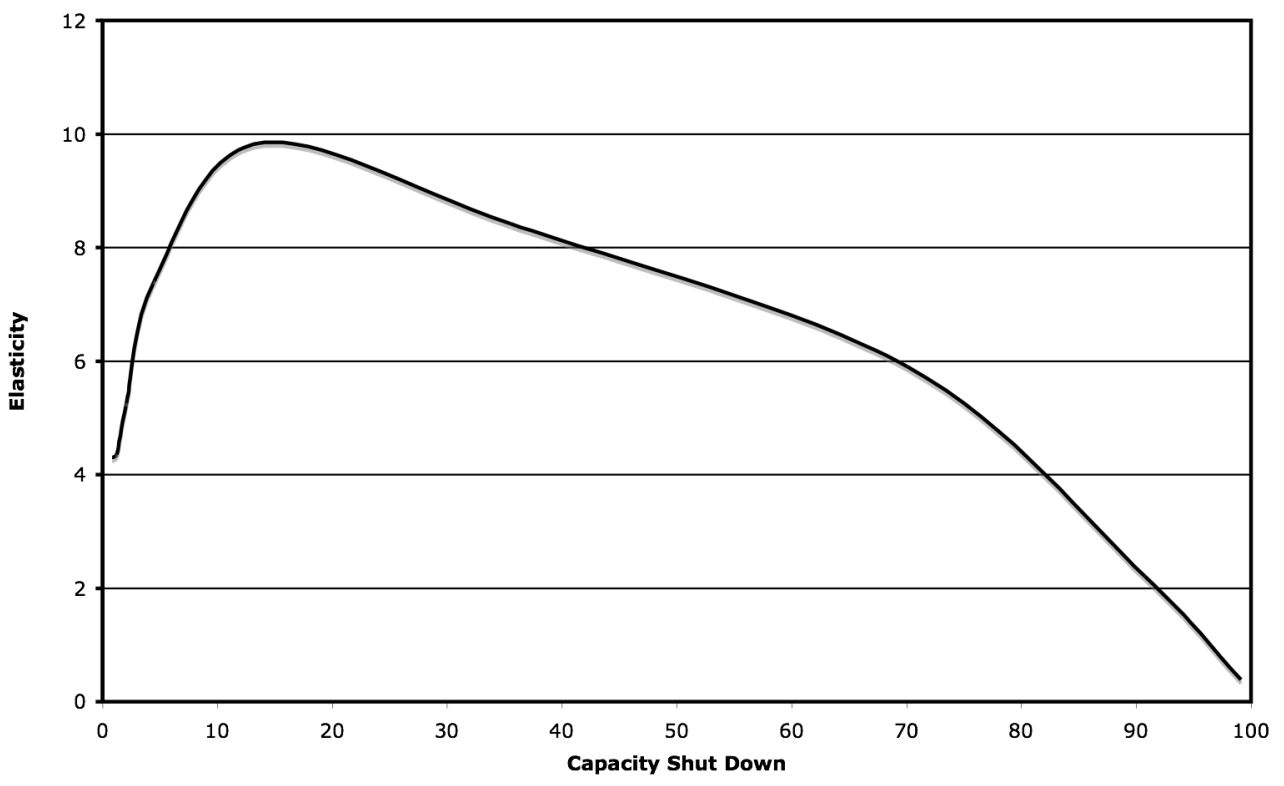

Elasticity of coal generators

Examining Figure 5, we see that the elasticity of coal generator capacity is above 6 for $\mathrm{S}<70$. A 1 percent change in the price of carbon dioxide emissions would cause 6 percent of coal generation capacity to shut down. The market for electricity is very complicated, and the price of electricity is very specific to time and location. However, the effect of a few generators being shut down by Enron Corp. on the price of electricity in California in 2000 and 2001 suggests that there should be a careful study of the dynamics of introducing a market for carbon dioxide permits on the market for electricity. 
There is a debate over whether a market for carbon dioxide or a carbon tax would more effective. In a world of perfect certainty, both policies are essentially equivalent and the debate is over the distributional implications of the policies. In a world with uncertainty, the merits of the policy may depend on the relative slopes of the benefits curve and the cost of the mitigation curve. A tax is preferable if the absolute value of the slope of the benefits curve is smaller than the absolute value of the slope of the cost curve. A market is preferable when the opposite is true. ${ }^{12}$ Our contribution to this debate is separate from this question and is more limited. Ninety percent of the coal generation capacity in the United States has heat rates between 9,500 BTU/kWh and $11,000 \mathrm{BTU} / \mathrm{kWh}$. Our concern is that this concentration of coal generation capacity, coupled with the high elasticity of coal generation to the carbon price, could result in a volatile market for electricity. An argument for a market in coal generation permits is that a market price for carbon dioxide emissions would lead to efficient allocation of resources. However, if coal generation capacity is sensitive to the price of carbon dioxide, then a market in coal generation permits could introduce instability. ${ }^{13}$

\section{Total Reduction in Carbon Dioxide}

The three sources of carbon dioxide are coal (2,125 billion MT), natural gas (1,242 billion MT), and petroleum $(2,436$ billion MT). Of this amount, the production of electricity accounts for 1,946 billion MT from coal, 263 billion MT from gas, and 40 billion MT from petroleum. In calculating the reduction in carbon dioxide from a charge on carbon dioxide emissions, we will calculate the following: 1) the reduction in carbon dioxide that comes from the displacement of coal generators by gas generators; 2) the reduction in carbon dioxide that comes from the decrease in the consumption of natural gas in domestic and commercial heating and industry as a result of a charge on carbon dioxide emissions; and 3) the reduction in carbon dioxide that comes

\footnotetext{
${ }^{12}$ See Stern, N., The Stern Review, pp. 351-354.

${ }^{13}$ Any definitive statement about the stability of the market for electricity would require a very careful modeling of a dynamic multi-market system with the added complication that a market in carbon dioxide permits for United States generators does not yet exist. The feedback in such market may involve multiple lags. Generator capacity may be a lagged function of the price of carbon dioxide permits. The price of electricity may be a lagged function of generator capacity and price of carbon dioxide permits may be a lagged function of the price of electricity. Such lags, coupled with the high elasticity of coal generator capacity, suggest the possibility that the dynamics of such a market could be very volatile. See Nordhaus, W. "Life After Kyoto: Alternative Approaches to Global Warming Policies." A discussion of the market for carbon dioxide permits in Europe can be found in Alberola and Chevallier (2009), pp.51-79.
} 
from the decrease in the consumption of petroleum as a result of a charge on carbon dioxide emissions. We will ignore the effects of a charge on carbon dioxide emissions on the nonfuel use of coal because the nonfuel use of coal accounts for approximately 2 percent of carbon dioxide emissions, and we do not have estimates of the price elasticity for the various nonfuel uses of coal. ${ }^{14}$

Let $a_{1}(R)$ be the carbon intensity for generators with a heat rate $R$. The fraction of carbon dioxide produced by these generators is $a_{1}(R) \gamma(R)$. The cumulative density function for the emission of carbon dioxide is

$$
Y(R)=A_{1} \int_{0}^{R} a_{1}(t) \gamma(t) d t
$$

where $A_{1}$ is chosen such that

$$
A_{1} \int_{0}^{\bar{R}} a_{1}(R) \gamma(R) d R=1
$$

Recalling that $a_{2}$ is the carbon intensity of gas, the total net reduction in carbon dioxide achieved by replacing coal generators by gas generators is given by

$$
X_{1}(\pi)=B_{1} A_{1} \int_{0}^{R(\pi)}\left[a_{1}(t)-a_{2}\right] \gamma(t) d t
$$

where $B_{1}$ is the base amount of carbon dioxide emitted by coal generators before the introduction of the price of carbon dioxide.

There are other reductions in the emissions of carbon dioxide resulting from the cost of carbon dioxide caused by increased costs of the petroleum and natural gas not used in electrical generation. The reduction for gas and petroleum $j=2,3$, respectively, is given by

\footnotetext{
${ }^{14}$ See http://www.eia.doe.gov/oiaf/1605/ggrpt/flowchart.html.
} 


$$
X_{j}=B_{j}\left(\frac{\beta_{j} \pi}{p_{j}+\frac{\beta_{j} \pi}{2}}\right) \eta_{j}
$$

where $B_{j}$ is the carbon dioxide emission for source $\mathrm{j}$ in the absence of constraints. Gas for domestic and commercial heating and industry corresponds to $\mathrm{j}=2$, and petroleum corresponds to petroleum. $p_{j}$ is the price per unit (dollars per $1000 \mathrm{ft}^{3}$ for $\mathrm{j}=2$, dollars per barrel for $\mathrm{j}=3$ ); $\eta_{j}$ is the price elasticity; and $\beta_{i}$ is carbon intensity per unit in metric tons. We are assuming that the elasticity for gas is $\eta_{2}=.3$ and the elasticity for petroleum is $\eta_{3}=.2 .{ }^{15}$ The term $\left(\frac{\beta_{j} \pi}{p_{j}+\frac{\beta_{j} \pi}{2}}\right)$ is the percentage change in price and thus $-\left(\frac{\beta_{j} \pi}{p_{j}+\frac{\beta_{j} \pi}{2}}\right) \eta_{j}$ is the percentage change in quantity. The values of the parameters are $B_{2}=880$ million $\mathrm{MT}, B_{3}=2,436$ million MT, $\beta_{2}=.053 \frac{\text { metric tons }}{1,000 \text { cubic } \mathrm{ft} .}, \beta_{3}=.342 \frac{\text { metric tons }}{\text { barrel }}$. Total 2008 carbon dioxide emissions in the United States were 5,814 million MT. The percentage reduction in total carbon dioxide is then

$$
X=\frac{B_{1} A_{1} \int_{0}^{R(\pi)}\left[a_{1}(t)-a_{2}\right] \gamma(t) d t+B_{2}\left(\frac{\beta_{2} \pi}{p_{2}+\frac{\beta_{2} \pi}{2}}\right) \eta_{2}+B_{3}\left(\frac{\beta_{3} \pi}{p_{3}+\frac{\beta_{3} \pi}{2}}\right) \eta_{3}}{5,814} .
$$

\footnotetext{
${ }^{15}$ We are using the elasticity for gas from the Hartley and Medlock World Gas Model, p. 391. Estimates of the elasticity of motor fuels range from 0 to 0.1 in the short run and 0.4 to 0.7 in the long run. Based on our conversations with Hartley and Medlock, we are using 0.2 . If we use an elasticity of 0.6 , then at a carbon dioxide price of $\$ 55 / \mathrm{MT}$, the reduction in the consumption of petroleum would increase from 1.9 percent to 5.7 percent. For a very nice discussion of the range of estimates of elasticities in the literature, see James C. Bartis et al., Producing Liquid Fuels from Coal, pp. 146-149.
} 
If we assume that $\pi=40$, a sample calculation for the fractional reduction in carbon dioxide from petroleum is

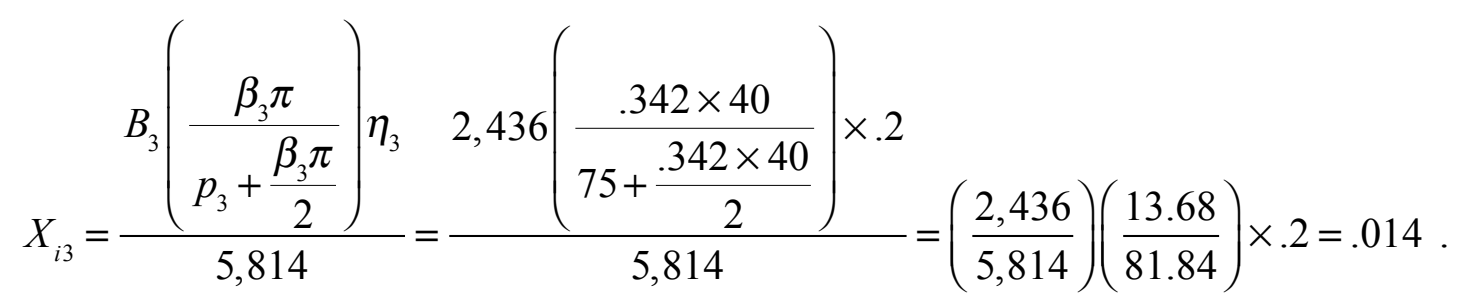

\section{Table 1}

\begin{tabular}{|r|r|r|r|r|r|}
\hline \multicolumn{6}{|c|}{ Displacement of Coal by Gas Generators and the Effects of Carbon } \\
Dioxide Costs on Oil and Natural Gas
\end{tabular}

Table 1 gives the reduction in carbon dioxide from all sources that results from the price effects of carbon dioxide charges in the range of $\$ 25$ to $\$ 55$ per metric ton with the assumptions about costs and elasticities made heretofore.

Let us pause to summarize. The values for the price of carbon dioxide depend on the assumptions about the price of coal, the price of gas, and the elasticities for gas and petroleum. However, for plausible values of the relative prices of coal and gas, the general shape of the curve comes from the distribution of the heat rates of coal generators. The implication seems to be that cap-and-trade could result in a reduction on the order of 20 percent of carbon dioxide emissions achieved by replacing coal generators with gas generators. The carbon dioxide prices will vary over a fairly small range in the process. Thus for a carbon dioxide price of \$30/MT or less, more than 90 percent of the coal generation capacity would be in operation, but a carbon 
dioxide price of $\$ 45 / \mathrm{MT}$ would cause 94 percent of the generation capacity to shut down (see Table 1). However, this price of $\$ 45$ per metric ton of carbon dioxide would only result in an approximately 3 percent reduction in emissions of carbon dioxide from other uses of natural gas and petroleum. Once coal generators are replaced, further reductions require substantial increases in the price of carbon dioxide. In electricity generation, natural gas would have to be replaced by nuclear power or other non-carbon sources of electricity.

The relationship between the price of carbon dioxide and the price of petroleum, and the price of a gallon of gasoline and diesel fuel at the pump, depends upon both the amount of carbon dioxide emitted when the fuel is burned and the amount of carbon dioxide created in the exploration, production, refining, and distribution process. Thus, we are reluctant to estimate the effect of the cost of carbon dioxide on the price of the delivered fuel. As a minimal reference point, for carbon dioxide at $\$ 45$ per ton, the cost of the carbon dioxide emitted when a gallon of gas is burned is 40 cents per gallon and 1.6 cents per kWh for gas-generated electricity.

The concentration in the distribution of coal generator capacity limits the range of carbon dioxide prices that are viable without completely eliminating coal generators. Prices for carbon dioxide emissions that eliminate coal-generated electricity should not result in a substantial reduction in the consumption of petroleum and natural gas that is not used in electrical generation. This suggests that it may be useful to have separate policies to regulating electricity coal generation and transport fuels. 


\section{Table 2}

\begin{tabular}{|r|r|r|r|r|r|r|}
\hline \multicolumn{2}{|c|}{ Displacement of Coal by Gas Generators and the Effects of Carbon Dioxide } \\
Costs on Oil and Natural Gas
\end{tabular}

\section{Sensitivity to the Price of Gas and Coal}

Critical parameters in the calculations of the price of carbon dioxide are the price of natural gas and the price of coal. The price of natural gas is volatile and difficult to forecast. The current (March 2010) price of gas delivered to electrical generators is in the $\$ 4.50$ to $\$ 5$ per 1,000 cubic feet range; however, the price was as high as $\$ 12$ per 1,000 cubic feet in 2008. It would take approximately 13.3 trillion cubic feet of natural gas per year to replace the electricity currently being produced by coal generators. ${ }^{16}$ Current U.S. production is on the order of 20 trillion cubic feet per year. Expert opinion is that prices in the range of $\$ 6$ to $\$ 8$ may be sufficient to induce a supply increase of 6.5 trillion cubic feet. The market price of coal is more difficult to define, as coal is more heterogeneous than gas. However, the price of coal delivered to utilities ranges from

\footnotetext{
$\dagger$ The price of carbon dioxide emissions was calculated for a price of coal of $\$ 1.50 / \mathrm{MMBtu}$ and a price of gas of \$5/MMBtu.

${ }^{16}$ We use the formula: $\mathrm{ft}^{3}=\frac{\mathrm{kwh} \times \mathrm{BTU} / \mathrm{kwh}}{\mathrm{BTU} / \mathrm{ft}^{3}}=\frac{2 \times 10^{12} \times 6.8 \times 10^{3}}{1.028 \times 10^{3}}=13.23 \times 10^{12} \mathrm{ft}^{3}$. Data from Energy Information Administration/Electric Power Annual 2007, p. 16, Table 1.1; and Du and Parsons, Update of Cost of Nuclear Power, p. 36.
} 
\$0.88 per MMBTU (\$15 short ton, 8,500 BTU/lb) to \$4 per MMBTU (\$105 short ton, 13,000 BTU/lb). ${ }^{17}$

The purpose of this model is not to forecast the price of carbon dioxide, but to provide a simple transparent model for calculating the price of carbon dioxide as a function of assumed fuel prices. We have used some of the current prices of coal and gas to calculate the price of carbon dioxide emissions.

A way to calculate the sensitivity of the price of carbon dioxide to the price of fuels is to calculate the price of carbon dioxide that would shut down a given fraction of the coal generating capacity as a function of fuel price. For example, we can calculate the price of carbon dioxide emissions that would shut down 70 percent of coal generating capacity. This would require shutting down coal generators with heat rates greater than $10,000 \mathrm{BTU} / \mathrm{kWh} .{ }^{18}$ From equation (9),

$$
\pi_{k}=\frac{b_{2}+\left[6.8 q_{2}-\left(R_{k} \times 10^{-3}\right) q_{1}\right]+\left(d_{2}-d_{1 j}\right)}{a_{10} R_{k}-a_{2}}=17.1 q_{1}+11.63 q_{2}+6.84
$$

\section{Table 3}

\begin{tabular}{|l|r|r|r|r|}
\hline \multicolumn{7}{|c|}{ Carbon Dioxide Price that will shut down 70 percent of coal generators } \\
Heat Rates greater than 10,000 BTU/kWh \\
\hline
\end{tabular}

Forecasting the price of gas and coal for the next 20 years is beyond our expertise. However, we feel that any forecast about the price of gas and coal must be conditional on policy. The price of

${ }^{17}$ EIA, http://www.eia.doe.gov/cneaf/coal/page/arc/table 3.4.html, http://tonto.eia.doe.gov/FTPROOT/coal/newsmarket/coalmar040704.html and EIA, http://www.eia.doe.gov/cneaf/coal/page/special/tbl2.html.

${ }^{18}$ A heat rate of 10,000 , for the example, was chosen because it is near the mean of the distribution and simple to compute. 
gas will depend substantially on the increased demand for gas from electrical generation. The demand for gas will depend on policy decisions about nuclear power and other renewables.

The other question is U.S. policy with respect to coal. At the present time, most of the coal mined in United States is used for electrical generation. If the United States shuts down coalfired generators, one would expect the price of coal to drop. However, the United States exports coal, and the price of coal in the United States should be the export price. It would be ironic if the result of cap-and-trade is that the United States exports coal to produce carbon dioxide abroad.

\section{Conclusions}

This paper calculates the cost of a carbon dioxide constraint-such as would result from capand-trade and other similar policies that restrict the output of carbon dioxide- by modeling the displacement of coal by gas in the production of electricity. Electrical production accounts for approximately 40 percent of the carbon dioxide produced in the United States. Of that amount, coal produces about 33 percent of total U.S. carbon dioxide emissions. We assume that, at present and for at least the next decade, the most important process of reducing carbon dioxide emissions in the United States will be through the displacement of coal by natural gas, and that this process will determine the price of carbon dioxide emissions. This assumption permits us to calculate the price of carbon dioxide in a relatively simple model with parameters that are available in the literature. The two independent variables are the price of coal and natural gas as fuels. The displacement of coal by gas in electrical generation is an assumption. It may be that some future technological breakthrough may invalidate this assumption. However, with current technology, replacing all existing coal generation plants with modern state-of-the-art coal generators would reduce carbon dioxide emissions by only 5 percent.

An important element in our calculation is the distribution of heat rates of coal generators. The heat rate is the amount of energy necessary to produce one kilowatt of electricity. The units are BTU per kilowatt-hour. Approximately 90 percent of coal generators in the United States have heat rates between $9,500 \mathrm{BTU} / \mathrm{kWh}$ and $11,500 \mathrm{BTU} / \mathrm{kWh}$. This concentration in the heat rates 
of coal generators is what determines the shape of the curve that relates the price of carbon dioxide emissions to a reduction in carbon dioxide. This concentration of heat rates also restricts the range over which carbon dioxide prices are effective in managing the displacement of coal by gas. In the sample calculations in the paper, a carbon price of approximately \$30/MT will shut down 10 percent of coal generator capacity. An additional increase of $\$ 15$-resulting in a carbon dioxide price of $\$ 45 / \mathrm{MT}$ - will shut down 90 percent of coal generator capacity. Calculating the carbon dioxide price for various values of the price of coal and gas results in shifts of the curve, but the property of a narrow operating band remains.

This narrow band of prices has two interesting implications. First, the price of carbon dioxide that eliminates coal generation is not sufficiently high to have a large impact on the consumption of petroleum. To put it another way, any carbon dioxide price that would significantly reduce the consumption of transport fuels would have to be of a level that would completely shut down coal generators.

Second, the narrow range for the price of carbon dioxide means that the elasticity of coal generator capacity with respect to the price of carbon dioxide emissions is very high. This means that the supply of coal generator capacity would very sensitive to the price of carbon dioxide emissions that could result from cap and trade. The high elasticity of coal generators coupled with the fact that short run demand for electricity is very inelastic creates the possibility that cap and trade will result in high volatility in the market for electricity.

At the present time, it appears that bills currently being considered by Congress may be modified to apply only to utilities. ${ }^{19}$ Based upon our research, we believe it is prudent to decouple utilities and transportation fuels for the purposes of carbon emissions policy. It would also be our recommendation that Congress adopt a carbon tax focused on electricity generation. Our work suggests an initial 20 percent reduction in carbon dioxide emissions could come from the transition from coal to gas in electrical generation. This approach carries several benefits. First, the electricity generation infrastructure in the United States is already in the process of conversion to natural gas as coal-powered infrastructure ages, so Congress would only be

\footnotetext{
${ }^{19}$ See The Economist, March 20, 2010, p. 32.
} 
expediting an inevitable process. Second, there is spare natural gas capacity within the system. ${ }^{20}$ Third, a carbon tax would not introduce volatility to the market for electricity.

Subsequent carbon emission reductions could come from a more efficient vehicle fleet. New regulations require the efficiency of the vehicle fleet to improve by 30 percent. In 15 to 20 years, a more efficient vehicle fleet might reduce carbon dioxide emissions after the gains from transitioning electricity generation from coal to gas are exhausted. This conjecture is beyond the scope of the model.

${ }^{20}$ See Kaplan, Displacing Coal with Generation from Existing Natural Gas-Fired Power Plants, 2010. 


\section{Appendix}

\section{Technology}

We are modeling the price of carbon dioxide during the transition from coal generation to gas generation. We will assume that there are two kinds of firms producing base load electricity. One class of firms indicated by the subscript 1 produces base load electricity using coal generators. They have a stock of coal generators that is heterogeneous, as we assume that coal generators vary in efficiency. The other class of firms uses gas generators indicated by the subscript 2 . We assume that all gas generators supplying base load electricity are modern generators and that these firms are paying a capital cost that reflects the price of new investment. The key assumptions are:

1. Coal and modern gas generators are base load sources of power. Output is always positive if the generators are being operated as base load sources of power.

2. Coal generators cannot be cycled. Output is constant if the generator is in operation.

3. The capital cost of gas generators is the market rate and there are no quasi-rents.

\section{Market for Electricity}

The price electricity $p(t)$ is assumed to be cyclical to reflect daily, weekly, and seasonal variations in demand. We will not make any assumptions about long-term trends. We will assume that firms know $p(t)$. We will assume that the representative firm has a planning cycle of length $T$. The planning cycle is the period of time over which investment decisions are made and carbon dioxide permits are allocated.

\section{Coal Generators}

Consider a representative firm that produces electricity from coal. Coal generators are heterogeneous and differ in their efficiency as measured by their heat rate defined in British Thermal Units (BTU) per kilowatt-hour. A coal generator indexed by $j$ is assumed to have a heat rate $R_{j}$ where $\mathrm{j}=1, N\left(\mathrm{~N}=\right.$ the number of generators owned by the firm). Define $x_{1 j}(t)$ as the 
electricity produced per day by the representative firm using a generator $\mathrm{j}$ with a coal generator with a heat rate $R_{j}$. Recall we assume that coal generators are a base load source of electricity and cannot be turned on just to supply peak load power. If it is possible to operate inefficient coal generators to provide peak load power, the problem becomes substantially more complicated. To address this problem we will assume that the firm chooses a constant level of operation over the operating cycle, so that

$$
x_{1 j}(t)=x_{1 j}
$$

for $t$ in $[0, T]$. Note that $x_{1 j}$ can be zero if the plant is uneconomical.

The assumption that the output of a plant is constant over the planning period is made for mathematical simplicity, but it is not innocuous. In fact, it is not the optimum strategy. There are cases when discounting would result in marginal plants continuing to operate in the short term if the losses were at the end of the time period.

The amount of fuel a given generator burns to produce one megawatt hour (MWh) of electricity is proportional to its heat rate. We define the fuel cost per MWh of a coal generator with the heat $R_{j}$ as

$$
c_{1 j}=\frac{R_{j}}{10^{3}} \times q_{1}
$$

where $q_{1}$ is the cost of coal in dollars/MMBTU (million British thermal units). The other variable cost is the sum of overhead and maintenance costs, $d_{1 j}$. Because our data sources assume it, we are forced to assume the nonfuel variable cost is proportional to electrical output and given by $\left(c_{1 j}+d_{1 j}\right) x_{1 j}$.

We will assume that the representative firm owns a heterogeneous stock of coal generators, $K_{1 j}, j=1, N$. Each generator owned by the firm has a capacity constraint defined by 


$$
x_{1 j} \leq K_{1 j}
$$

Total electricity produced by the representative firm that uses coal generators is given by

$$
x_{1}=\sum_{j=1}^{N} x_{1 j}
$$

The amount of carbon dioxide per unit of output (metric tons per MWh) emitted by a coal generator with a heat rate $R_{j}$ is a linear function of the heat rate

$$
a_{1 j}=\frac{\bar{a}_{11}}{\bar{R}_{1}} R_{j}
$$

where $\bar{a}_{11}$ and $\bar{R}_{1}$ are parameterized from the 2009 update to the MIT study. The amount of carbon dioxide by produce by a coal generator with a heat rate $R_{j}$ is given by

$$
y_{1 j}=a_{1 j} x_{1 j} .
$$

The total production of carbon dioxide by the representative coal-generating firm is at time $t$ given by the equation

$$
Y_{1}(t)=\int_{0}^{t} \sum_{j=1}^{N} y_{1 j}(s) d s=\int_{0}^{t} \sum_{j=1}^{N} a_{1 j} x_{1 j} d s
$$

Or from (A-4), the total amount of carbon dioxide produced by coal in the period $[0, T]$ where $\mathrm{T}$ has units of days is

$$
Y_{1}(T)=\int_{0}^{T} \sum_{j=1}^{N} a_{1 j} x_{1 j} d t
$$

We will assume that at the start of the planning period, $t=0$, the firm is given an allocation $Z_{1}(0)$ on the amount of carbon dioxide the firm can emit in the production of electricity during the period defined by $\mathrm{T}$. 
We will assume that there is a market of carbon dioxide permits and the firm can buy or sell these permits. The price of permits might fluctuate over a wide range during the period covered and a market in $\mathrm{CO}_{2}$ emission futures is certain to develop. We cannot begin to model these uncertainties. Let us assume that the firm is not interested in speculation in this market, and instead plans to hedge by purchasing or selling contracts for $\mathrm{CO}_{2}$ over the period with a certain delivery price which, including the net of the futures sale, is $\pi$. [As a minor simplification, we assume the present cost (or income) from the futures contract is increased (or decreased) by the imputed interest to $\mathrm{T}$ in the magnitude of $\pi]$. Let $\xi_{1}(T)$ be the net purchase or sale of permits. Thus, the firm has constraint

$$
Z_{1}(T)+\xi_{1}(T)-Y_{1}(T)=0
$$

Or using (A-8), this can be written as

$$
Z_{1}(0)+\xi_{1}(T)-\int_{0}^{T} \sum_{j=1}^{N} a_{1 j} x_{1 j} d t=0
$$

The firm would maximize net revenue in the period

$$
\sum_{j=1}^{N} x_{1 j} \int_{0}^{T}\left[p(t)-\left(c_{1 j}+d_{1 j}\right)\right] d t-\pi \xi_{1}(T)
$$

subject to the capacity constraints (A-2) and the dioxide carbon constraint (A-10). Note that to simplify the algebra, we are not discounting. ${ }^{21}$

\footnotetext{
${ }^{21} \mathrm{We}$ initially solved the problem in the more general case with an objective function of the form $\sum_{j=1}^{N} x_{1 j} \int_{0}^{T} e^{-r t}\left[p(t)-\left(c_{1 j}+d_{1 j}\right)\right] d t-e^{-r T} \pi \xi_{1}(T)$. This led to integrals of the form $\int_{0}^{T} e^{-r t} d t$ that cancelled without changing the final result.
} 
Since output is constant, this can be solved as a static problem. The Lagrangian for this optimization is

$$
L=\left\{\begin{array}{l}
\sum_{j=1}^{N} x_{1 j} \int_{0}^{T}\left[p(t)-\left(c_{1 j}+d_{1 j}\right)\right] d t-\pi \xi_{1}(T)+\phi_{1 j}\left[K_{1 j}-x_{1 j}\right] \\
+\lambda_{1}\left[Z_{1}(T)+\xi_{1}(T)-\int_{0}^{T} \sum_{j=1}^{N} x_{1 j} a_{1 j}\right]
\end{array}\right\}
$$

The first order conditions with respect to $x_{1 j} \geq 0, j=1, N$ and $\xi_{1}(T)$ are

$$
\begin{gathered}
\frac{\partial L}{\partial x_{1 j}}=\int_{0}^{T}\left[p(t)-\left(c_{1 j}+d_{1 j}\right)-\lambda_{1} a_{1 j}\right] d t-\phi_{1 j} \leq 0 \\
x_{1 j} \frac{\partial L}{\partial x_{1 j}}=x_{1 j}\left\{\int_{0}^{T}\left[p(t)-\left(c_{1 j}+d_{1 j}\right)-\lambda_{1} a_{1 j}\right] d t-\phi_{1 j}\right\}=0
\end{gathered}
$$

$$
\frac{\partial L}{\partial \xi_{1}(T)}=\lambda_{1}-\pi=0
$$

where $\lambda_{1}>0$ is the Lagrange multiplier associated with the carbon dioxide constraint and $\phi_{1 j} \geq 0, \mathrm{j}=1, N$ are the Lagrange multipliers associated with capacity constraints. The restriction that $x_{1 j} \geq 0, j=1, N$ requires the use of the Kuhn-Tucker theorem for (A-13). However, since $\xi_{1}(T)$ is not constrained to be nonnegative, the condition given by (A-14) holds with equality. ${ }^{22}$

\section{Gas Generators}

Since we are modeling the displacement of the existing coal generator stock by new gas generators, we are assuming that all gas generators are identical with the same heat rate. We will define the fuel cost per MWh of a gas generator as $c_{2}$ and the amount of carbon dioxide (metric

\footnotetext{
${ }^{22}$ See Leonard and Van Long, Optimal Control Theory and Static Optimization in Economics, Cambridge University Press, (1992) pp. 52-53.
} 
tons per MWh) emitted by a gas generator as $a_{2}$. The other costs are capital costs, $b_{2}$, and overhead and maintenance costs, $d_{2}$. These costs are from the 2009 update to the MIT study. The amount of carbon dioxide by produce by a gas generator is given by

$$
\frac{d Y_{2}(t)}{d t}=a_{2} x_{2}(t)
$$

To avoid problems with the indeterminacy of the size of the firm when the technology is linear, we will assume that the representative gas-generating firm has a capacity constraint of $K_{2}$ and

$$
x_{2}(t) \leq K_{2} \text {. }
$$

The firm leases capital at a lease rate, $\beta_{2}$, that eliminates quasi-rents. The dimensions of a lease rate are $\frac{\text { dollars }}{\text { MWh Capacity }} \times($ lease period $)$.

We will assume that at the start of the planning period, $t=0$, the representative gas generator firm is given an allocation $Z_{2}(0)$ for the amount of carbon dioxide the firm can emit in the production of electricity during the period $0 \leq t \leq T$.

The firm can buy or sell these permits at a price $\pi$. Let $\xi_{2}(T)$ be the net purchase or sale of permits. Thus the firm has constraint

$$
Z_{2}(0)+\xi_{2}(T)-Y_{2}(T)=0
$$

The objective function can be written as

$$
W=\int_{0}^{T}\left[p(t)-c_{2}-d_{2}\right] x_{2}(t) d t-\pi \xi_{2}(T)+\lambda_{2}\left[Z_{2}(0)+\xi_{2}(T)-Y_{2}(T)\right]
$$


The Hamiltonian for this optimization is

$$
H=\left[p(t)-c_{2}-d_{2}+\theta_{2}(t) a_{2}\right] x_{2}(t)+\phi_{2}(t)\left[K_{2}-x_{2}(t)\right]
$$

where $\theta_{2}(t) \geq 0$ is the costate variable associated with the carbon dioxide constraint and $\phi_{2}(t) \geq 0$ is the Lagrange multiplier associated with capacity constraints. Let $*$ denote the optimal value of a variable. Using Pontryagin's Maximum Principle, the costate variable, $\theta_{2}(t)$, must satisfy the differential equation

$$
\frac{d \theta_{2}^{*}(t)}{d t}=-\frac{\partial H}{\partial Y_{2}(t)}
$$

since the Hamiltonian is not an explicit function of $Y_{2}(t), \frac{\partial H}{\partial Y_{2}(t)}=0$ and $\theta_{2}^{*}(t)$ is constant in $[0, T]$

Pontryagin's Maximum Principle states that the Hamiltonian must be maximized with respect to the control variables at each point in time for the optimal value of the costate variable. The control variable is $x_{2}(t) \geq 0$. The Kuhn-Tucker condition for $x_{2}(t)$ is

$(\mathrm{A}-21)$

$$
\frac{\partial H}{\partial x_{2}}=\left[p(t)-\left(c_{2}+d_{2}\right)-\theta_{2}(t) a_{2}-\phi_{2}(t)\right] \leq 0
$$

$$
x_{2}^{*}(t) \frac{\partial H}{\partial x_{2}}=x_{2}^{*}(t)\left[p(t)-\left(c_{2}+d_{2}\right)-\theta_{2}(t) a_{2}-\phi_{2}(t)\right]=0
$$

Then the transversality condition for $\theta_{2}(T)$ is ${ }^{23}$

$$
\theta_{2}(T)=\frac{\partial W}{\partial Y_{2}(T)}=\lambda_{2}
$$

\footnotetext{
${ }^{23}$ See Leonard and Van Long, Optimal Control Theory and Static Optimization in Economics, Cambridge University Press, (1992) pp. 248-251.
} 
and the first order condition with respect to $\xi_{2}(T)$ is

$$
\frac{\partial W}{\partial \xi_{2}(T)}=\lambda_{2}-\pi=0
$$

If $x_{2}^{*}(t)>0$, then $\left[p(t)-\left(c_{2}+d_{2}\right)-\theta_{2}(t) a_{2}-\phi_{2}(t)\right]=0$. Using (A-22), (A-23) and integrating

$$
\int_{0}^{T} p(t) d t=\left(c_{2}+d_{2}\right) \int_{0}^{T} d t+\pi a_{2} \int_{0}^{T} d t+\int_{0}^{T} \phi_{2}(t) d t
$$

Similarly, if $x_{1 j}>0$ then $\int_{0}^{T}\left[p(t)-\left(c_{1 j}+d_{1 j}\right)-\pi a_{1 j}\right] d t-\phi_{1 j}=0$ and

$$
\int_{0}^{T} p(t) d t=\left(c_{1 j}+d_{1 j}\right) \int_{0}^{T} d t+\pi a_{1 j} \int_{0}^{T} d t+\phi_{1 j}
$$

We can use (A-25) and (A-26) to solve for $\pi$ :

$$
\pi=\frac{\left(c_{2}+d_{2}\right) T+\int_{0}^{T} \phi_{2}(t) d t-\left(c_{1 j}+d_{1 j}\right) T+\phi_{1 j}}{\left(a_{2}-a_{1 j}\right) T}
$$

Let us assume that coal generators with the $k$-th heat rate are marginal. That is to say, any generators whose heat rate is greater than $R_{k}$ would shut down, then $\phi_{1 k}=0$ and

$$
\pi=\frac{\left(c_{2}+d_{2}\right)-\left(c_{1 j}+d_{1 k}\right)}{\left(a_{2}-a_{1 k}\right)}+\frac{\int_{0}^{T} \phi_{2}(t) d t}{\left(a_{2}-a_{1 k}\right) T} .
$$

$\phi_{2}(t)$ is how much the firm is willing to pay for capacity at time $t$. Since $K_{2}$ is a constant over $[0, T]$ and the technology is linear,

$$
\int_{0}^{T} \phi_{2}(t) d t=\beta_{2}
$$


where $\beta_{2}$ is the lease cost of a unit of gas generation capacity. Recall that the units of $\beta_{2}$ are $\frac{\text { dollars }}{\text { Mwh Capacity }} \times($ lease period $)$.

$$
\int_{0}^{T} \phi_{2}(t) d t=b_{2} \int_{0}^{T} d t=b_{2} T
$$

where $b_{2}$ is can be interpreted as the average fixed cost per megawatt hour for the gas generators. Thus, the term

$$
\frac{\int_{0}^{T} \phi_{2}(t) d t}{T}=\frac{\beta_{2}}{T} \equiv b_{2} .
$$

So:

$$
\pi=\frac{\left(c_{2}+d_{2}\right)-\left(c_{1 k}+d_{1 k}\right)+b_{2}}{\left(a_{2}-a_{1 k}\right)}
$$

The value of $\pi$ is the price of carbon dioxide emissions that makes a coal generator with a heat rate $R_{k}$ marginally competitive with a modern gas generator with the parameters in the MIT study. The coal generator with a heat rate $R_{k}$ is at the shutdown point. 


\section{References}

Alberola, Emilie and Julien Chevallier. 2009. European Carbon Prices and Banking Restrictions: Evidence from Phase I. The Energy Journal 30 (3).

Bartis, James T., Frank Camm, and David S. Ortiz. 2008. Producing Liquid Fuels from Coal. RAND Corporation.

BENTEK Energy, LLC. 2010. How Less Became More: Wind, Power and Unintended Consequences in the Colorado Energy Market. Available at http://www.bentekenergy.com/WindCoalandGasStudy.aspx.

Deutch, John, et al. 2003. The Future of Nuclear Power: An Interdisciplinary MIT Study. Massachusetts Institute of Technology.

Deutch, John, et al. 2009. 2009 Update of the 2003 MIT Report: The Future of Nuclear Power. Massachusetts Institute of Technology. Available at http://web.mit.edu/nuclearpower/pdf/nuclearpower-update2009.pdf.

The Economist. Cap-and-trade's last hurrah. March 20, 2010.

Energy Information Administration (EIA). EIA 923 (formerly the 920/906) database. http://www.eia.doe.gov/cneaf/electricity/page/eia906_920.html.

. Electric Power Industry 2008: Year in Review. Available at

http://www.eia.doe.gov/cneaf/electricity/epa/epa_sum.html. . Emissions of Greenhouse Gases in the United States, 2008. Available at http://www.eia.doe.gov/oiaf/1605/ggrpt/flowchart.html. . Emissions of Greenhouse Gases in the United States, 2007. Available at http://www.eia.doe.gov/oiaf/1605/ggrpt/figure 1.html. . Natural Gas Navigator. Available at http://www.eia.doe.gov/dnav/ng/hist/n3045us3m.htm. . Electric Power Annual, 2007, p. 16, Table 1.1 a. . http://www.eia.doe.gov/cneaf/coal/page/arc/table 3.4.html. . Coal News and Markets. Week of July 4, 2004. Available at http://tonto.eia.doe.gov/FTPROOT/coal/newsmarket/coalmar040704.html. . U.S. Coal Supply and Demand, 2009 Review. Available at http://www.eia.doe.gov/cneaf/coal/page/special/tbl2.html. 
Hartley, Peter and Kenneth Medlock. 2006. The Rice World Gas Trade Model. In Natural Gas and Geopolitics: From 1970 to 2040, eds. David G. Victor, Amy M. Jaffe, and Mark H. Hayes. Cambridge, UK: Cambridge University Press.

Kaplan, Stan Mark. 2010. Displacing Coal with Generation from Existing Natural Gas-Fired Power Plants. Congressional Research Service. Available at http://assets.opencrs.com/rpts/R41027_20100119.pdf.

Kolstad. Charles D. 1996. Fundamental irreversibilities in stock externalities. Journal of Public Economics, 62: 85-125.

Laffont, Jean-Jacques and Jean Tirole. 1996. Pollution permits and compliance strategies. Journal of Public Economics 60: 221-233.

Leonard, Daniel and Ngo van Long. 1992. Optimal Control Theory and Static Optimization in Economics. Cambridge, UK: Cambridge University Press.

Medlock, Kenneth B. The Rice World Gas Trade Model. Paper presented at CEC Workshop, James A. Baker III Institute for Public Policy, Rice University, June 16, 2009, in Houston, Texas.

Nordhaus, William D. 2005. Life After Kyoto: Alternative Approaches to Global Warming Policies. Yale University. Available at http://www.econ.yale.edu/ nordhaus/kyoto_long_2005.pdf.

Stern, N. 2007. The Stern review on economics of climate change. Cambridge University Press. Available at http://webarchive.nationalarchives.gov.uk/+http://www.hmtreasury.gov.uk/independent_reviews/stern_review_economics_climate_change/stern_review _report.cfm.

Du, Yanbo, Du and John E. Parsons. May 2009. Update of Cost of Nuclear Power. Center for Energy and Environmental Policy Research, Massachusetts Institute of Technology. Wolak, Frank. May 2010. Regulatory Barriers to Lowering the Carbon Content of Energy Services. Program on Energy and Sustainable Development, Stanford University. Available at http://pesd.stanford.edu/publications/regulatory_barriers_to_lowering_the carbon_content of_energy_services/. 